\title{
THE RELATION OF UNEMPLOYMENT COMPENSATION TO THE BROADER PROBLEM OF RELIEF
}

\author{
EveIINe M. BurNs*
}

Unemployment compensation is often referred to as the "first line of defense" in the total program for unemployment relief. It is important, therefore, to discover where this line should be drawn. The relative importance of unemployment compensation in a comprehensive relief program will, of course, be determined by the initial scope of the compensation system (i.e., what employments and types of workers are covered by the laws), the amount of benefit payable, its duration, the length of the waiting period that must elapse before the unemployed worker is entitled to benefits, and the stringency of the qualifying conditions.

If the remaining states set up laws under the Social Security Act on the pattern of the ro laws already in existence, the scope of unemployment compensation is likely to be relatively small and the residual relief system correspondingly large. The Social Security Act visualizes the exclusion of agriculture, domestic service, employment with non-profit-making concerns and with employers of less than eight workers. Some of the state laws are more generous in their scope but except in the case of noncompetitive employments, fear of interstate competition will prevent them from greatly exceeding the federal limitations.

As a general rule the existing laws limit benefits to 50 per cent of wages, with a maximum of $\$ 15$ and in some cases a minimum of $\$ 5$ or $\$ 7$. It is obvious that in the low-paid trades benefits based on $5^{\circ}$ per cent of wages will frequently require supplementing from other (and often relief) sources. The duration of benefits is, as a rule, I5 weeks, a relatively short period, in comparison with the average of European plans. This short duration will make for an extremely large residual problem in periods of depression in view of the fact that unemployment tends to be concentrated on a portion only of workers. The average waiting period of 3 weeks may in normal times involve no necessity for a supplementary system, although it should be noted that if workers must carry themselves during this period they will have

* B.Sc. (Econ.), I920, Ph.D. (Econ.), 1926, London School of Economics, University of London. Member of Graduate Department of Economics, Columbia University, since 1928. Consultant to Committee on Economic Security, 1934. Member of Faculty, London School of Economics, 192x-6. Laura Spelman Travelling Fellowship 1926-8. Author of Wages and the State (1926); The Economic World (r927) (with A. R. Burns); Toward Sorial Security (I936). Contributor to economic periodicals. 
diminished reserves of savings with which to supplement benefits limited to $5^{\circ}$ per cent of wages during the next 15 weeks. The qualifying conditions also limit the significance of unemployment compensation in the total relief structure. All plans limit the right to draw benefits to those who have been employed for not less than a specified number of weeks during a defined preceding period. Many of them relate the duration of benefit to the length of previous employment. In consequence, in severe depressions many workers, although occupationally within the scope of unemployment compensation laws, will fail to qualify for benefit.

In deciding the part to be played by unemployment compensation in the total relief system, a number of considerations must be balanced. The decision must take into account ( $\mathrm{I}$ ) the appropriateness of the financial methods normally resorted to in unemployment compensation as compared with those available or actually utilized in financing the residual system, (2) the appropriateness of the type of benefit provided in unemployment compensation plans as compared with the forms of benefit available in the residual system, and (3) the administrative convenience of unemployment compensation as compared with other types of relief. Unfortunately these considerations often lead to contradictory results.

\section{Financial Considerations}

It has become usual to associate unemployment compensation with a specific method of financing: namely, the collection of contributions from employers and workers, to which there is frequently added a predetermined contribution from general taxation. In the American plans the major emphasis is placed upon contributions from employers. This limitation is due partly to the Administration's own preference for a "self-sustaining" social insurance system (i.e., one which receives no contribution from general taxation), partly to the belief that payroll taxes can be utilized as a device for stabilizing employment, and partly to the opposition of organized labor to a workers' contribution. These considerations, together with the incitement given in the tax-offset device of the Social Security Act to setting up plans financed by a $2.7 \%$ payroll tax on employers, account largely for the fact that all American plans provide for such a tax, as the major source of unemployment compensation funds. Taxes on workers are provided for in a number of cases (though often limited to $50 \%$ of the taxpayer's tax rate) but only in one case is there any provision for a contribution from general taxation to provide for anything more than part of the costs of administration.

Thus, if the self-sustaining social insurance principle be adhered to, the relative importance of unemployment compensation in the total relief set-up will be determined by the amount of money it is deemed expedient to raise by taxes on payrolls and perhaps also on wages. The appropriateness of these taxes for financing unemployment relief, is, however, coming to be more and more questioned. Admittedly 
the tax on employers permits differentiation on the basis of risk and thus some stimulus to preventive action. But the extent to which by taking thought employers can control unemployment, is severely limited, and the narrow margin given by a payroll tax of $2.7 \%$ does not permit of any great degree of differentiation. Payroll taxes have the further disadvantage that they can be evaded, or in any case reduced by increasing mechanization. In periods of depression they may be more deterrent to enterprise than other types of taxes. Furthermore, their ultimate incidence is very uncertain. A contribution from workers can be defended as a method of selecting those workers whe are to receive preferential treatment, but the low level of wages precludes any significant recourse to this type of tax.

As a result of these limitations the funds raised for unemployment compensation, if confined to these taxes, will be relatively small and there will be a need for a correspondingly large residual relief program. Whether or not other tax sources should be drawn upon in order to permit of an expanded unemployment compensation program will, from the financial angle, depend very largely upon the provision made for financing the residual relief system. If this provision is disorderly, or if the taxes available and the distribution of responsibility between various authorities are such as to lead to undesirable economic or political consequences, it may be preferable (in order to reduce this unwieldy residual burden to a minimum) to extend the scope of the unemployment compensation system. This may necessitate providing the additional funds out of general taxation.

Both Great Britain between r 920 and I93I and Germany from 1930 onwards have demonstrated the political and economic disadvantages of defining the scope of the unemployment compensation system by reference to the yield of certain types of taxes, regardless of the consequences on the size of the residual problem. In both cases the entire relief structure was disorganized because of the unwillingness of the central governments to shoulder the rapidly increasing residual relief bill, and the inability of local authorities to do so, thanks to the lack of elasticity of local taxing and borrowing resources.

In England there resulted an undesirable expansion of the unemployment compensation system because, in the absence of an appropriately financed residual relief system, this was the only way to relieve local finances of the growing relief burden. In Germany the narrow scope of the insurance system was retained and, after a period in which the mounting relief costs demoralized local finances and led to undesirable economies in local welfare activities, its scope was restricted even further, in order that the surplus insurance funds might be used by the federal government for assisting the local authorities. But in each case, as the result of identifying certain types of benefit with specific methods of financing or types of authority, the form of benefit given to the unemployed was determined not by any rational criteria but by the possibilities of shifting financial responsibility from one authority to another. 
The Appropriateness of Various Types of Benefit

The second factor which must be taken into account is the kind of benefits available through unemployment compensation as compared with those available in the residual relief program. From the point of view of the recipient, the characteristic that separates unemployment compensation is the more favorable conditions under which the contractual benefits are given. No means test is applied, and, as a general rule, there is no pressure to take work at less, or substantially less, than prevailing wages for the duration of compensation rights. Frequently the insured worker is protected against compulsion to take work other than that to which he is accustomed, or in places distant from that in which he resides.

On the other hand, the money received may or may not be greater than under the alternative relief system. For the low paid workers, limited under compensation to $50 \%$ of wages, relief may be preferable, for it is usually distributed on the basis of family needs. Where the residual relief system involves a work program (either in the form of public works or work relief) it may again be preferable. The sum of money obtained is likely to be greater than under unemployment compensation and the average worker prefers a job to idleness.

From this point of view it may be argued that unemployment compensation is more suitable to short-period unemployment, leaving work relief and possibly higher benefits for those workers who have exhausted their unemployment compensation benefits. But if compensation is limited to workers in certain employments, provision must be made for the short-period unemployed in these excluded trades. If they are to be treated under the residual system in the same way as the insured workers who have exhausted their benefit rights (i.e., if the residual relief system is a uniform one), difficulties may arise. Insured workers may find that as a result of paying wage taxes they will receive, for the first weeks of unemployment, benefits smaller in amount than those received by workers employed in the excluded trades. The only difference between the insured and non-insured workers would then consist in the conditions under which benefit is paid; the latter might, for example, receive benefits not as a right but only on demonstration of need, etc. It remains to be discovered whether the average insured worker will regard the differences in conditions for benefit (in contrast to the amount and nature of benefits) as an adequate justification for the contribution that he may be called upon to make. The alternative is to treat the short-period unemployed in the excluded employments on an entirely different basis from either the insured worker or the long-period unemployed who have exhausted insurance benefits. But this will involve yet a third relief system.

In any case, the existence of preferential relief systems in a society which is unwilling to allow workers and their families to starve for lack of income, will necessitate some ultimate, though possibly deterrent, form of maintenance. If unemployed workers on work programs cannot be fired for inefficiency because there is no alternative relief system, the economic value and social desirability of work relief may 
be reduced. The most effective control against malingering and other abuses available to an unemployment compensation system disappears if denial of insurance benefit is no hardship because the benefits of the residual relief system are more generous.

Once again both Great Britain and Germany have demonstrated the undesirability, if not the ultimate impossibility, of attempting through an unemployment insurance or compensation system to segregate certain workers for special types of benefit, regardless of the types of benefit available in the residual system. In England the residual relief system until 193 I was so unsatisfactory to the recipient as compared with the preferential compensation system that there was irresistible political pressure to extend the latter to workers who, if the original principles of the law had been adhered to, should have been excluded. In Germany the relief system was severely criticized by social workers and economists after 1930, because maintenance of the preferential insurance benefits regardless of their relationship to those available under the residual system, involved discrepancies in treatment for apparently similarly situated workers, that were difficult to justify.

The nature of the benefits given by unemployment compensation and other forms of relief has also its economic aspects. It is undesirable that workers should be put on work relief projects immediately they lose their ordinary jobs, since they would thus be prevented from seeking reëmployment during the period when their chances are greatest. Moreover, it is rare that work relief projects offer unemployed workers jobs of the kind to which they have been accustomed. It is doubtful whether workers (especially the skilled or semi-skilled) should be expected to undertake these different types of work until it is evident that there is no longer any demand for their normal services. Work relief may then be appropriate as a method of re-training, or to maintain morale. Since work relief is likely to be more expensive and more troublesome to administer than straight cash relief, it should presumably be confined to those unemployed who are most in need of this type of benefit. The long-period unemployed suggest themselves as obvious candidates. But it is doubtful whether, if work relief is to be the normal type of benefit offered by the residual system, I5 weeks is a reasonable point at which to draw the line between workers who should receive cash benefits and those who should be relieved through a work program.

There is yet another economic aspect to this problem. An unemployment relief system which provides benefits as a right without pressure to accept jobs at less than prevailing wages involves an economic risk to the community as a whole. It is essentially a relaxation of the pressure on workers to conform to market prices. Such a relaxation will postpone wage readjustments which may be a serious matter if there is a general depression due largely to maladjustment in wage rates. The extent of this risk will be determined by the period for which these "non-pressure" benefits are given. Some relaxation of the pressure during the first weeks of unemployment is in the general interest. It is undesirable that workers should be pressed to seek 
unfamiliar jobs or jobs at less than prevailing rates until it becomes clear that the demand for their services in their old employments or at the old wage level is unlikely to revive. It is, however, questionable whether the 15 weeks breathing spell allowed for in the average American system is long enough to permit the true state of affairs to be diagnosed.

It is, moreover, impossible to know at the beginning of a trade recession whether the remedy lies in a general reduction of wages. But it is clear that this relaxation of pressure on wage rates cannot be indefinite. Thus the proper scope of unemployment compensation in the total relief situation will depend partly on the extent to which any community is prepared to run the risk of postponing desirable economic readjustments. It cannot be determined without taking into account the underlying economic situation. A richer community can afford to take a greater risk by extending the period for which unemployment compensation benefits are payable than a poorer community. It is improbable that this decision can be made once and for all.

\section{Administrative Considerations}

The final group of considerations that must play a part in determining the scope of unemployment compensation are administrative. As compared with other types of relief, unemployment compensation has both administrative disadvantages and advantages. It is probably more complicated as a method of collecting the necessary funds than a system relying on the proceeds of general taxation. It involves the keeping of elaborate records and the levying and collecting of special taxes. On the other hand, this work can be done in an orderly way and is spread evenly trom year to year. There is no peak load. As a result of this routine accumulation of records unemployment compensation presents great advantages as a method of paying benefits.

In the first place, the realm of administrative discretion is greatly reduced and payment becomes much more nearly automatic. The claim of a worker to be qualified can be checked from the existing records, no means test is involved, and the right of the workers to refuse jobs at less than prevailing wages greatly simplifies the problem of the administrator. For a defined number of weeks of unemployment it is not necessary to decide whether in each individual case there should be pressure to accept work below prevailing wages, and, in many systems, work that is unfamiliar. The determination of the amount of benefit is also automatic (in contrast with home relief where each worker's benefit depends upon his individual needs).

Secondly, the type of benefit given greatly simplifies the administration. Unemployment compensation calls only for the payment of a cash benefit. Thus the problems associated with work relief, the selection of appropriate workers and projects, and the determination of wage rates and conditions of work do not arise. Indeed, its administrative convenience is one of the great arguments in favor of unemployment compensation as a method of unemployment relief. The relative part to be 
played by unemployment compensation in the total relief set-up will be partly determined by the extent to which this administrative convenience would outweigh possible economic or financial disadvantages of extending the system. If the cost of compiling records of payments is considerable, a system which utilizes this convenient mechanism for paying benefits only during the first 15 weeks of unemployment fails to reap much advantage from the heavy overhead involved in the permanent record-keeping system.

\section{Concluston}

Unfortunately the three basic considerations discussed in the preceding sections often lead to conflicting results. It would indeed be remarkable if the sum raised by exploiting wage and payroll or any other taxes to the degree indicated by fiscal and economic considerations should be exactly that needed to finance an unemployment compensation system of a magnitude found to be desirable by reference to our other two sets of considerations. Yet the foreign experience suggests that there can be no satisfactory partial or unintegrated solution of the problem of unemployment relief. Where can a beginning be made? Do some considerations out-weigh others?

Since no one type of tax is obviously both appropriate and adequate to finance an unemployment relief program, the scope of an unemployment compensation system should be determined by reference to the economic costs and administrative convenience of benefits of this type as compared with those of other available forms of benefit, i.e., by reference to the second and third of the considerations discussed in this paper. The institutional set-up should, however, make provision for calm and periodic revision of this decision. Some kinds of benefits are more costly than others from both the financial and the broader economic point of view, and can be more easily borne at some times than others.

The problem of financing is secondary. The approximate total sum to be spent on relief will be set by the decisions as to the types of benefit to be given and the relative importance of each in the total system. The financial problem then becomes one of discovering appropriate and available taxes. If it is desired to finance unemployment compensation at least in part by wage and payroll taxes, and these should prove inadequate to carry a plan of the scope indicated by social, economic and administrative considerations, the additional funds must be supplied from some other source. Within the limits of this brief paper it is not possible to discuss the details of the financing of the residual relief system. 